\title{
Reply on "What Is the Role of Surgeons When Implanting a Totally Implantable Venous Access Device to Prevent Immediate Complications?"
}

\author{
Eun-Joo Jung ${ }^{1}$, Dae-Yong Hwang ${ }^{1,2}$ \\ Department of Surgery, Colorectal Cancer Center, ${ }^{1}$ Konkuk University Medical Center, ${ }^{2}$ Konkuk University School of Medicine, Seoul, Korea
}

To the editor:

We appreciate your great interest in our article [1]. First of all, I agree with the comments concerning the risk of a blind technique and the need to check the catheter's position during the procedure. In terms of safety, a surgical cut-down procedure on the cephalic vein or the external jugular vein is excellent, especially for avoiding fatal complications such as a pneumo- or a hemothorax [2-4]. Also, ultrasonography guidance makes the procedure safer $[5,6]$. I think that the main issue is whether or not ultrasonography or fluoroscopy is available in the operation room. In fact, in the past, neither ultrasonography nor fluoroscopy was freely available in the operation rooms at Konkuk University Medical Center. However, recently with the availability of these medical devices, ultrasonography is routinely used to insert the totally implantable central venous access devices (TICVAD) and to check the position of the catheter tip during the procedure, as you recommended. As to the terminology of port migration, your comment is correct, and changing "port migration" to "dislocation/ dislodgement of port chamber" would be much clearer, as you mentioned [7].

Additionally, I would like to comment on the classification of complication according to the period. The standard of early and late complications is different in different reports in the literature. Knebel et al. [7] classified complications as perioperative and postoperative. You have classified them as immediate, early and late complications or as early and late complications $[2,4]$. As you have indicated in your comments, complications within 24 hours

Correspondence to: Dae-Yong Hwang, M.D.

Department of Surgery, Colorectal Cancer Center, Konkuk University Medical Center, Konkuk University School of Medicine, 120 Neungdong-ro,

Gwangjin-gu, Seoul 05030, Korea

Tel: +82-2-2030-5111, Fax: +82-2-2030-5112

E-mail: hwangcrc@kuh.ac.kr

(c) 2015 The Korean Society of Coloproctology

This is an open-access article distributed under the terms of the Creative Commons Attribution NonCommercial License (http://creativecommons.org/licenses/by-nc/3.0) which permits unrestricted noncommercial use, distribution, and reproduction in any medium, provided the original work is properly cited. after the procedure are important because they are related to the surgeon or to technical failures. We were interested in the surgeon's influence on the complications. Therefore, we wanted to focus on complications within 24 hours after the surgery, which we defined as early complications.

As to your comment on heparin usage, we indicated the usage of $10 \mathrm{~mL}$ of diluted heparin. This means that a total of $10 \mathrm{~mL}$ of diluted heparin solution was used to flush and fill the catheter before and after TICVAD insertion into the central vein. Also, we used a solution of heparin sodium (500 IU of heparin in $10 \mathrm{~mL}$ of isotonic saline) for flushing.

\section{CONFLICT OF INTEREST}

No potential conflict of interest relevant to this article was reported.

\section{REFERENCES}

1. An H, Ryu CG, Jung EJ, Kang HJ, Paik JH, Yang JH, et al. Insertion of totally implantable central venous access devices by surgeons. Ann Coloproctol 2015;31:63-7.

2. Di Carlo I, Barbagallo F, Toro A, Sofia M, Lombardo R, Cordio S. External jugular vein cutdown approach, as a useful alternative, supports the choice of the cephalic vein for totally implantable access device placement. Ann Surg Oncol 2005;12:570-3.

3. Di Carlo I, Pulvirenti E, Mannino M, Toro A. Increased use of percutaneous technique for totally implantable venous access devices. Is it real progress? A 27-year comprehensive review on early complications. Ann Surg Oncol 2010;17:1649-56.

4. Di Carlo I, Cordio S, La Greca G, Privitera G, Russello D, Puleo S, et al. Totally implantable venous access devices implanted surgically: a retrospective study on early and late complications. Arch Surg 2001;136:1050-3.

5. Biffi R, Toro A, Pozzi S, Di Carlo I. Totally implantable vascular access devices 30 years after the first procedure. What has changed and what is still unsolved? Support Care Cancer 2014;22:1705-14. 


\section{Coloproctology Eun-Joo Jung, et al.}

6. Di Carlo I. A complete message for avoiding fatal complications from central venous port placement. J Am Coll Surg 2009;209: 287; author reply 287.

7. Knebel P, Lopez-Benitez R, Fischer L, Radeleff BA, Stampfl U,
Bruckner $\mathrm{T}$, et al. Insertion of totally implantable venous access devices: an expertise-based, randomized, controlled trial (NCT 00600444). Ann Surg 2011;253:1111-7. 